\title{
SEMANTiCS Konferenz 2016
}

Vom 12. bis 15. September wird die Bach-Stadt Leipzig erneut zum Mittelpunkt der internationalen Semantic Web Entwicklung. Auf der 12. internationalen Linked-Data-Konferenz SEMANTiCS 2016 diskutieren Forscher, Entwickler und Unternehmen die aktuellen Lösungen, Herausforderungen und die Zukunft semantischer Technologien und ihrer kommerziellen Anwendung.

Im Mittelpunkt der Konferenz steht die aktuelle Frage, wie Linked Data Services den Aufwand der Informationsbeschaffung und -verwertung in Unternehmen weiter reduzieren können. Unternehmen haben heutzutage damit zu kämpfen, dass immer mehr Arbeit auf immer weniger Mitarbeiter verteilt wird. Zugleich steigt die Menge und Komplexität von Daten exponentiell. Deshalb braucht es Systeme, die flexibel und smart auf die wachsenden Anforderungen reagieren. So können nicht nur versteckte Kosten minimiert werden, sondern auch Wissenslücken schnell geschlossen und Projektverzögerungen frühzeitig verhindert werden.

Das international zur Weltspitze gehörende Leipziger Kompetenznetzwerk für semantische Technologien wird die Kon- ferenz aktiv mitgestalten, Trends diskutieren und aktuelle Projekte vorstellen. Neben dem Hauptprogramm mit verschiedenen renommierten Keynote Speakern gehören zu den Kern-Events:

- Vorstellung konkreter semantischer Unternehmenslösungen durch das Verbundprojekt der regionalen Linked-Data-Wirtschaft „Linked Enterprise Data Service“ (LEDS)

- Weiterentwicklung und Erläuterung des einzigartigen offenen Wissensgraphen DBpedia

- Schulungen zu Linked Data Management wie zum Beispiel PoolParty der Semantic Web Company

- Wissenschaftliche Workshops, organisiert von der renommierten Leipziger Forschergruppe „Agile Knowledge Engineering and Semantic Web“ (AKSW) des Institut für Angewandte Informatik (InfAI)

- Best Practices führender Unternehmen

Veranstaltungsort ist die Universität Leipzig, Campus Augustusplatz, Leipzig.

Weitere Informationen sowie die Möglichkeit zur Registrierung finden Sie auf der Internetseite: http://2016.semantics.cc

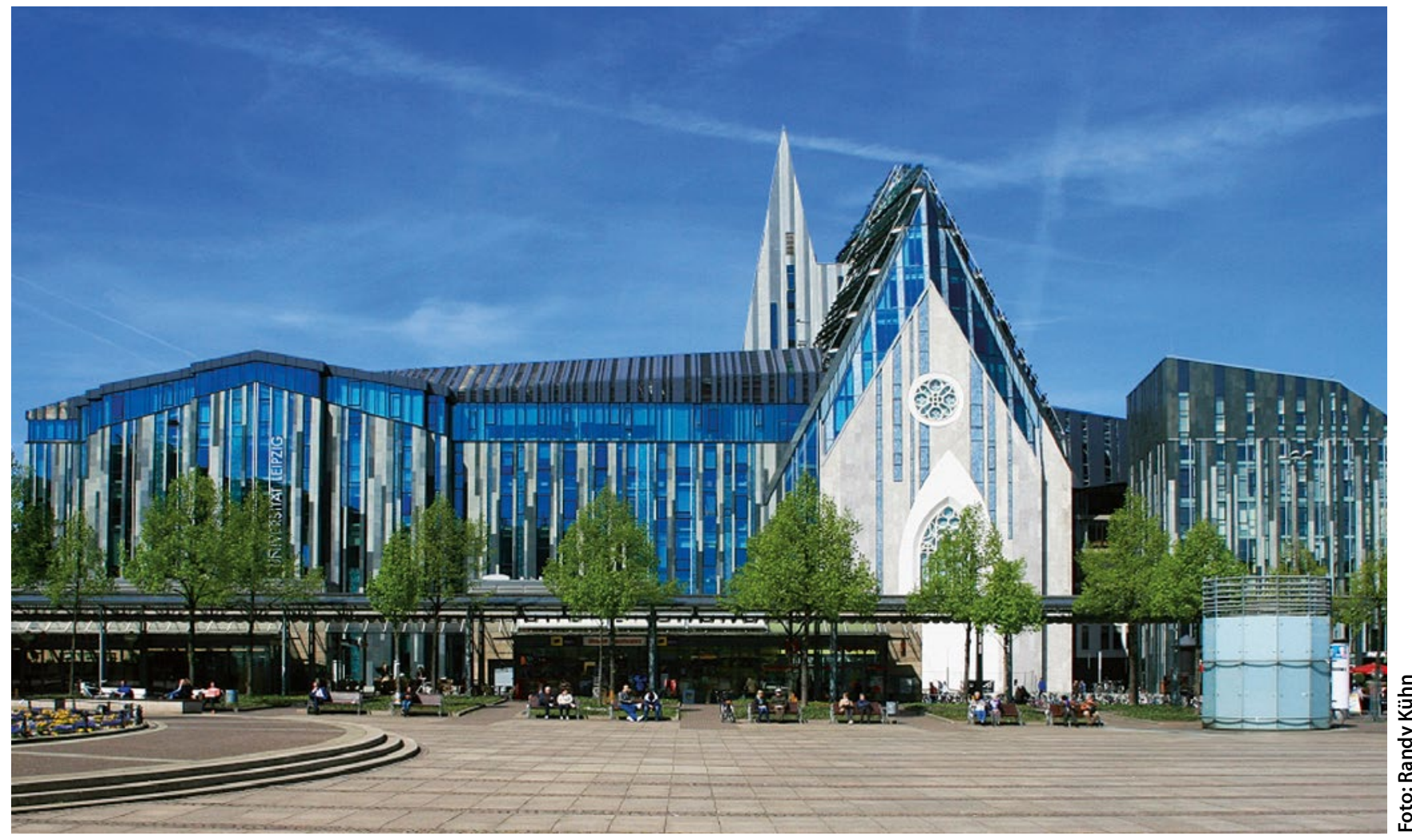

Universität Leipzig 